\title{
The effect of a ready signal on the relationship between habit and drive variables in human eyelid conditioning
}

\author{
WILLIAM C. GORDON* \\ and \\ ROBERT H. DUFORT $\dagger$ \\ Wake Forest University, Winston-Salem, N.C. 27109
}

Performance curves for high- and low-drive groups in human eyelid conditioning were shown to diverge across training trials if no ready signal was employed. Use of a ready signal acted to mask this diverging trend in other groups that differed in drive level.

The theory of conditioning proposed by Spence (1956) maintained that habit $(\mathrm{H})$ and drive or motivational (D) variables are related to each other in a multiplicative fashion. An important prediction from this assumption is that acquisition curves of groups differing in $\mathrm{D}$ should diverge across training trials $(\mathrm{a} \mathrm{H}$ variable). However, Prokasy (1967), in a review of several human conditioning studies, found little evidence to support the prediction of diverging performance curves. Prokasy correctly noted that, while several studies demonstrate an interaction between various D variables and the training trials variable, such an interaction indicates only that performance curves in these studies were not parallel. In most cases, these interactions were found by Prokasy not to be due to a divergence of performance curves across training trials.

While Prokasy's analysis seems to indicate that Spence's multiplicative postulate cannot be confirmed in human conditioning situations, it is equally likely that certain procedural operations or variables in the human conditioning paradigm act to mask the multiplicative relationship expected between $H$ and $D$ variables. It is the supposition of the present paper that the use of a ready signal (RS) in human conditioning studies might be one such procedural variable.

The RS has been used in numerous human classical eyelid conditioning studies to signal the impending onset of a trial. Dufort \& Kimble (1958) first demonstrated that Ss trained with a RS perform at a lower level than those trained without the signal. The tendency of the RS to depress performance has subsequently been well supported (e.g., McAllister \& McAllister, 1960; Klinger \& Prokasy, 1962). While the mechanism for this performance decrement is unclear, Turner (1966)

*Presently at Rutgers-The State University

tRequests for reprints should be sent to Robert $H$. Dufort, Department of Psychology, Wake Forest University, Winston-Salem, North Carolina 27109. Charles Richman sponsors this paper and takes full editorial responsibility for its contents. suggests that the RS might contribute to the learning of a general inhibitory "set" or "attitude" which is incompatible with the CR. According to this analysis, the RS itself is a learning variable for an inhibitory set. Thus, Spence's multiplicative postulate would predict that performance deficits due to a RS should be greater when D is high than when D is low. From this, it follows that the usual performance differences between highand low-D groups would be reduced in studies which employ a RS, and this reduction could mask the divergence of high- and low-D group performance curves across trials. In line with this reasoning, the present study will show that while performance curves of highand low-D groups do diverge across trials in at least one human conditioning situation, the use of a RS in this situation is sufficient to eliminate the diverging trend.

\section{METHOD}

Subjects and Apparatus

The Ss were 92 male introductory psychology students from Wake Forest University. Twenty-three Ss were assigned randomly to each of four groups. The apparatus was a standard soundproofed eyelid conditioning chamber described previously (Dufort, 1967).

\section{Procedure}

A 2 by 2 factorial design was employed, using a RS under high-D (RS-H) and low-D (RS-L) conditions and the absence of a RS under high-D (NRS-H) and low-D (NRS-L) conditions. The CS was an increase in the brightness of a lighted disk from a level of .24 to 1.08 apparent fc. The UCS was an airpuff of $3.5 \mathrm{psi}$, delivered to the corner of S's right eye. The CS had a duration of $560 \mathrm{msec}$, and the UCS was presented during the final $60 \mathrm{msec}$ of the CS. A CR was recorded when the response pen showed at least a $1-\mathrm{mm}$ deflection in the $200-516 \mathrm{msec}$ interval after CS onset (cf. Spence \& Ross, 1959).

Each $S$ received 55 CS-UCS conditioning trials, as well as 55 airpuff-alone trials, in a block randomized order. The airpuff-alone trials were used to define the high- and low-D conditions (cf. Spence et al, 1958). In the high-D groups, the unpaired airpuffs were 3.5 psi in intensity, while for the low-D groups the unpaired airpuff intensity was 1.0 psi. The RS, a buzzer of 1-sec duration, was presented at randomly varied intervals of 2,3 , or $4 \mathrm{sec}$ prior to CS onset. The RS preceded all 110 trials in the RS groups but was never presented in the NRS groups. For all Ss the intertrial interval averaged $20 \mathrm{sec}$.

\section{RESULTS}

Acquisition curves for the four groups appear in Fig. 1, which presents mean percent CR as a function of blocks of five conditioning trials. For purposes of statistical analysis, percent CR was converted to mean E values (see Spence, 1956). To determine the tendency of these acquisition curves to diverge across trials, a rank-order correlation, suggested by Prokasy (1967), was 


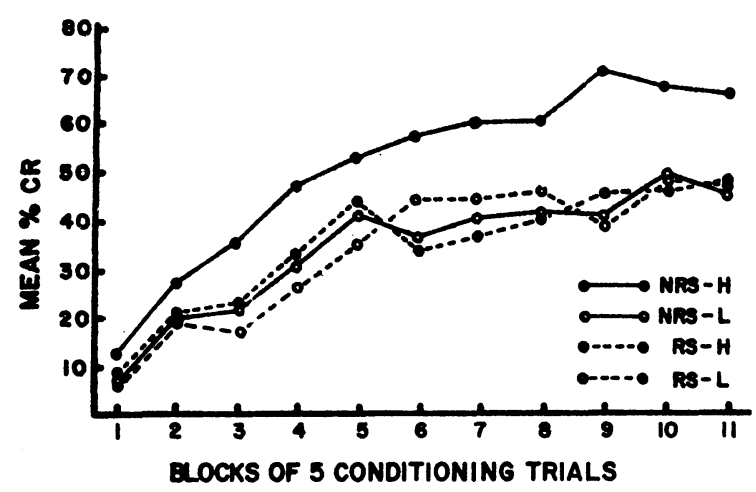

Fig. 1. Mean percent CR as a function of blocks of five conditioning trials.

employed. This test correlates the difference between two acquisition curves after a given trial block with the ordinal number of that trial block. Divergence would be indicated if a positive correlation of statistical significance were to result.

Using this test, a comparison of the high- and low-D groups in the NRS condition showed that the acquisition curves did diverge significantly across trials (rho $=.61$, $\mathrm{p}<.05)$. On the other hand, the high- and low-D groups in the RS condition failed to show a divergence (rho $=-.33, \mathrm{p}>.05)$.

\section{DISCUSSION}

Results of this study indicate that, given the present parameters, there is evidence for a divergence of high- and low-D acquisition curves across training trials only when no RS is used. While this result does not explain all failures to find a multiplicative relationship between $\mathrm{H}$ and $\mathrm{D}$ variables, it does suggest that Spence's multiplicative postulate does apply to the human classical conditioning paradigm. However, to find this relationship, it may be necessary to eliminate certain accessory procedures (e.g., a RS in this case) which are often employed in human conditioning experiments.

\section{REFERENCES}

Dufort, R. H. Eyelid conditioning as a function of UCS duration with drive equated. Journal of Experimental Psychology, 1967, 74, 321-323.

Dufort, R. H., \& Kimble, G. A. Ready signals and the effect of interpolated UCS presentations in eyelid conditioning. Journal of Experimental Psychology, 1958, 56, 1-7.

Klinger, B. I., \& Prokasy, W. F. A note on MAS score and the ready signal in classical eyelid conditioning. Psychological Reports, 1962, 10, 829-830.

McAllister, W. R., \& McAllister, D. E. The ready signal in eyelid conditioning. American Journal of Psychology, 1960, 73, 444-447.

Prokasy, W. F. Do $D$ and $H$ multiply to determine performance in human conditioning? Psychological Bulletin, 1967, 67, 368-377.

Spence, K. W. Behavior theory and conditioning. New Haven: Yale University Press, 1956.

Spence, K. W. Haggard, D. F., \& Ross, L. E. UCS intensity and the associative (habit) strength of the eyelid CR. Journal of Experimental Psychology, 1958, 55, 404-411.

Spence, K. W., \& Ross, L. E. A methodological study of the form and latency of eyelid responses in conditioning. Journal of Experimental Psychology, 1959, 58, 376-381.

Turner, B. B. Effects of ready signal upon eyelid conditioning. Journal of Experimental Psychology, 1966, 72, 11-14.

(Received for publication November 25, 1972.) 